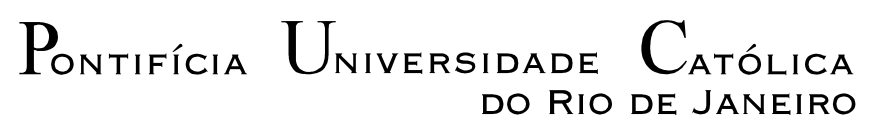

Alba Regina Loredo Gama Tamanini

\author{
CONTEMPLANDO A RESSEMANTIZAÇÃO DA \\ INTERAÇÃO NA SALA DE AULA DE INGLÊS COMO \\ LÍNGUAA ESTRANGEIRA: UMA PESQUISA-AÇÃO
}

Tese apresentada ao Programa de Pós-graduação em Estudos da Linguagem da PUC-Rio como requisito parcial para obtenção do título de Doutor em Letras/Estudos da Linguagem.

Orientadora: Profa. Maria do Carmo Leite de Oliveira 
Pontifícia Universidade Catálica

Alba Regina Loredo Gama Tamanini

\section{CONTEMPLANDO A RESSEMANTIZACÃO DA INTERAÇÃO NA SALA DE AULA DE INGLÊS COMO LÍNGUAA ESTRANGEIRA: UMA PESQUISA-AÇÃO}

Profa. Maria do Carmo Leite de Oliveira

Orientadora

Departamento de Letras - PUC-Rio

Profa. Inés Kayon de Miller

Departamento de Letras - PUC-Rio

Profa. Amitza Torres Vieira

UFJF

Profa. Fernanda Henriques Dias

UFRRJ

Profa. Isabel Cristina Rangel Moraes Bezerra

UERJ

Profa. Denise Berruezo Portinari Coordenadora Setorial do Centro de Teologia e Ciências Humanas - PUC-Rio

Rio de Janeiro, 23 de agosto de 2013. 
Todos os direitos reservados. É proibida a reprodução total ou parcial do trabalho sem autorização da universidade, da autora e do orientador.

\section{Alba Regina Loredo Gama Tamanini}

Graduada em Letras Português/Inglês pela Faculdade da Cidade em 1982. Especialista em Língua Inglesa pela UERJ em 1985. Mestre pelo Programa Interdisciplinar em Linguística Aplicada pela UFRJ em 2006. Ingressou no curso de Doutorado em Letras da PUC-Rio em 2009. É professora do Ensino Básico, Técnico e Tecnológico no Colégio Militar do Rio de Janeiro (CMRJ) desde 1998. É coordenadora pedagógica de inglês (nível intermediário) desse colégio desde 2000.

Ficha catalográfica

Tamanini, Alba Regina Loredo Gama

Contemplando a ressemantização da interação na sala de aula de inglês como língua estrangeira: uma pesquisa-ação / Alba Regina Loredo Gama Tamanini; orientadora: Maria do Carmo Leite de Oliveira. - 2013.

278 f. : il. (color.) ; $30 \mathrm{~cm}$

Tese (doutorado) - Pontifícia Universidade Católica do Rio de Janeiro, Departamento de Letras, 2013.

Inclui bibliografia

1. Letras - Teses. 2. Contemporaneidade e desafios educacionais. 3. Multiletramentos e ensino de ILE. 4. Redescrição sala de aula de ILE. 5. Jogo interacional. 6. Pesquisa-ação. I. Oliveira, Maria do Carmo Leite de. II. Pontifícia Universidade Católica do Rio de Janeiro. Departamento de Letras. III. Título. 


\section{Agradecimentos}

Agradeço, primeiramente, a Deus que, em seu amor infinito, colocou tantas pessoas amigas em meu caminho que possibilitaram concluir com êxito esta etapa de minha vida.

A Mauro, meu marido, meu porto seguro, pelo amor, companheirismo e apoio incondicional à minha vida profissional.

À minha querida mãe, Alice, por todo amor, carinho e apoio a mim dedicados em todos os momentos de minha vida.

Aos meus filhos queridos, Laís e Igor, presentes de Deus em minha vida, pelo carinho, apoio e, principalmente, pelo amor que foi um combustível essencial para a conclusão deste trabalho.

A toda minha família cujo apoio e compreensão foram essenciais a essa conquista: minhas irmãs Ana, Andréa e Patrícia (Saudades), minha querida sogra Olga Tamanini e cunhada Mery Tamanini que compreenderam minha ausência em diversos momentos.

Aos meus queridos colegas de trabalho do Colégio " $X$ " por seu apoio e torcida, em especial, aos chefes da seção de Idiomas, Professoras Ana Claudia dos Santos Tello e Carla Maria Miguel Alves Soares, pela valorização e incentivo às minhas atividades acadêmicas e, sobretudo, por proporcionar as condições necessárias para que eu pudesse me dedicar à conclusão desta pesquisa. Não posso deixar de agradecer o carinho de tantos outros amigos do meu contexto de trabalho - Ana Tereza, Menna Barreto, Rosane Pinho, Clara Pimentel, Marília Duarte, Sandra - que sempre me incentivaram com palavras de carinho e apoio ao meu trabalho.

À amiga Lúcia Pinheiro, pela interlocução sempre valiosa e, sobretudo, por suas palavras de incentivo, indispensáveis para que eu concluísse esta caminhada. 
A Danielle Lima, pela amizade, palavras de incentivo e de valorização de meu trabalho. E, ainda, por sua disposição em colaborar com a revisão do resumo da tese.

A Tatiana Miliante, pela presteza de sempre e leitura cuidadosa do capítulo teórico desta pesquisa.

A Rosemery Juck Schreiber, pela ajuda na redação e revisão do abstract desta tese.

À minha querida orientadora, Maria do Carmo Leite de Oliveira, pela amizade, confiança, palavras de incentivo, mas, sobretudo, pelos vastos saberes compartilhados de forma sempre alegre e estimulante.

À Professora Inés Kayon Miller, pelo convite aceito para compor minha banca examinadora e, também, por ser um exemplo de professora e pesquisadora que ajuda a tornar a sala de aula um espaço de descoberta e crescimento.

Aos professores membros da banca, pela oportunidade singular de interlocução acerca da pesquisa desenvolvida e por terem, gentilmente, aceitado o convite para participarem de minha defesa de tese.

Aos professores da PUC-RIO por tudo que aprendi ao longo dos quatro anos de doutorado, em especial à professora Barbara Hemais, por ter possibilitado a reorientação deste trabalho.

À PUC-Rio, pelos auxílios concedidos, sem os quais este trabalho não poderia ter sido realizado.

Aos funcionários da Secretaria de Letras, pelo atendimento sempre eficiente, em particular a Chiquinha, pela competência, ajuda e paciência com todos nós, os pós-graduados.

Ao professor da UFRJ Luiz Paulo da Moita Lopes que me acompanha desde a graduação e que fundou muito do que sou como professorapesquisadora. Muito obrigada pelos saberes compartilhados.

À professora Branca Falabella Fabrício pelos comentários enriquecedores e revisão cuidadosa da tese por ocasião da qualificação.

Aos meus alunos queridos, pela colaboração neste estudo e por representarem uma fonte constante de aprendizagem para mim. 


\section{Resumo}

Tamanini, Alba Regina Loredo Gama; Oliveira, Maria do Carmo Leite (Orientadora). Contemplando a ressemantização da interação na sala de aula de inglês como língua estrangeira: uma pesquisa-ação. Rio de Janeiro, 2013. 278p. Tese de Doutorado - Departamento de Letras. Pontifícia Universidade Católica do Rio de Janeiro.

Muitas das práticas construídas na sala de aula convencional não falam mais ao aluno de hoje e, por conseguinte, não motivam sua participação. Para essa geração, acostumada aos discursos altamente semiotizados e interativos das telas de TV e do computador, a escola convencional parece ser pouco atraente e nada desafiadora. Este estudo nasce a partir da associação desse panorama à falta de interesse e engajamento de muitos alunos nas aulas de inglês como língua estrangeira (ILE) no contexto onde atuo - uma instituição federal situada no Rio de Janeiro. Este trabalho traz reflexões sobre os efeitos da instauração de um programa de ações pedagógico-discursivas, norteado pela perspectiva dos multiletramentos, em uma turma de nível intermediário, do $9^{\circ}$ ano do ensino fundamental, utilizando a metodologia da pesquisa-ação. Com base em uma visão sociointeracional de ensino-aprendizagem e dialógica de linguagem, tem-se como objetivo contribuir para uma melhor compreensão de como a referida proposta pode favorecer a ressignificação da interação na aula de ILE, com vistas a promover um ambiente de ensino-aprendizagem mais colaborativo e com uma participação mais espontânea e efetiva daqueles alunos. Os dados foram gerados ao longo do ano letivo de 2010, por meio de gravações em áudio das conversas sobre textos midiáticos. À luz das contribuições da Análise da Conversa e da Sociolinguística Interacional, foram identificados quatro movimentos característicos do jogo interacional. A análise indicou que a construção de uma sala de aula participativa se dá em conjunto e demanda mudanças nas ações, práticas e regras típicas que regem a interação e a comunicação entre professores e alunos. Apontou ainda que os aprendizes se tornam menos passivos ao serem estimulados a participar do processo de gerenciamento das atividades, principalmente com tarefas que envolvam interação em pares ou em pequenos 
grupos e a discussão de temas instigantes ou relacionados à sua realidade. Constatou-se que as atividades realizadas contribuíram de forma efetiva para a solidificação dessa prática mais cooperativa, possibilitando não apenas a expansão de repertório de sentidos e esquemas de conhecimentos dos alunos, mas, sobretudo, levando-os a ter uma postura crítico-reflexiva. Esta investigação mostrou, por fim, que o uso de textos variados, em particular, vídeos do YouTube pode ser um caminho para chegar ao aluno e motivá-lo a participar de forma mais ativa, iniciando um processo de reconfiguração dos papéis de professor-alunos e contribuindo para uma reversão paulatina do modelo de interação da sala de aula. Isso se dá pela gama de temas atuais que o Youtube oferece e pelo fascínio que as telas exercem sobre os jovens. Dentre as principais mudanças observadas, destacam-se a ampliação da participação e a colaboração entre os aprendizes, dando-lhes um papel mais ativo e autônomo - o de colaborador ativo na interação -, confirmada pela tomada de turno, autosseleção e retroalimentação dos turnos de fala e pela atenção à fala dos colegas. Quanto ao professor, observa-se a solidificação de uma prática mais descentralizadora na condução da aula, expressa na redução de sua dominância discursiva e no exercício do papel de mediador ou observador do processo interacional.

\section{Palavras-chave}

Interação; Multiletramentos; Sala de aula de ILE; Pesquisa-ação. 


\section{Abstract}

Tamanini, Alba Regina Loredo Gama; Oliveira, Maria do Carmo Leite (Advisor). Contemplating the resemantization of interaction in EFL classroom setting: an action research. Rio de Janeiro, 2013. 278p. Ds. Thesis - Departamento de Letras. Pontifícia Universidade Católica do Rio de Janeiro.

Many of the practices constructed in conventional classroom settings no longer speak to the students of today, and thus don't trigger their participation. For this generation, accustomed to the highly semiotized discourses and the interactivity of the TV and computer screens, the conventional school seems to be neither appealing nor challenging. This research arises from the association of this scenario with the lack of interest and engagement of many students in the classes of English as a foreign language (EFL), in the context in which I work - a federal institution located in Rio de Janeiro. By means of an action research, this study raises reflections upon the effects of the implementation of a set of pedagogical and discursive procedures, guided by the perspective of multiliteracies, in a ninthgrade class of intermediate level of English from a junior high school. Based on a dialogical conception of language and a sociointeractional view of teachinglearning, it is intended to contribute to a better understanding of how this proposal can favor the redefinition of interaction in the EFL class. Such proposal envisages the promotion of a more collaborative teaching-learning environment as well as a more spontaneous and effective participation of those students. The data were generated throughout the year of 2010 by means of audio recordings of media text talk. In light of the contributions of the Conversation Analysis and Interactional Sociolinguistics, four defining movements of the interactional game have been identified. The analysis pointed out that the achievement of a participatory classroom is a joint construction and demands changes in actions, practices and typical rules that lead interaction and communication between teachers and students. It also emphasized that learners take a more active role when encouraged to participate in the management of the activities, mainly tasks that involve peer or small group interaction and discussions of thought-provoking themes more 
related to their reality. It was noticed that the activities performed contributed in an effective manner to the consolidation of a more cooperative practice, which allowed not only the expansion of the students' repertoire of meanings but also their knowledge schemata, taking them to develop a more reflective and critical attitude. This research finally showed that the use of different texts, particularly, videos from YouTube may be a way to approach the students and motivate them to participate more actively, and thus triggering a process of redefining the teacherstudents roles and contributing to the gradual redescription of the classroom interaction model. This happens due to the array of current themes offered by YouTube coupled with the fascination that screens exert on the young. Within the main changes observed, the ones that stand out are the broadening scope of participation and cooperation among learners, giving them a more active and autonomous role, that is, the one of active participants in the interaction, which is confirmed by turn-taking, self-selection and back-channeling of the turns of talk and by the attention driven to classmates' talk. As to the teacher's role, it has been observed the consolidation of a more decentralizing class management, expressed by the reduction of his discursive dynamics and his role as a mediator or observer of the interaction process.

\section{keywords}

Interaction; Multiliteracies; EFL Classroom Setting; Action Research. 


\section{Sumário}

$\begin{array}{ll}\text { 1. Introdução } & 17\end{array}$

$\begin{array}{ll}1.1 \mathrm{O} \text { despertar de um questionamento } & 18\end{array}$

2. Tecendo os fios da base teórica 25

2.1 Contemporaneidade e desafios educacionais 25

2.2 Multiletramentos e ensino de ILE 33

2.3 Interação e sala de aula 39

2.3.1. Visão Dialógica de Linguagem 41

2.3.2. Visão sociointeracional do processo de ensino-aprendizagem 44

2.4 Sala de aula convencional: limites à participação discursiva dos aprendizes e possibilidades de redescrição 48

2.4.1 A questão da assimetria no diálogo 51

2.4.2 Controle de tópicos 54

2.4.3 Um olhar sobre o padrão Iniciação-Resposta-Avaliação (IRA) e estrutura de participação 56

2.4.4 Arranjos espaciais em sala de aula 63

2.4.5 Sistema de troca de turnos $\quad 65$

2.5 Jogo interacional na sala de aula: enquadres, alinhamentos, esquemas de conhecimento e pistas de contextualização 69

2.5.1 Identidades e Papéis 75

3. Abordagem metodológica $\quad 81$

3.1 A opção pelo paradigma interpretativista 81

3.1.1 A figura do pesquisador 84

3.2 A escolha da PA 86

3.3 Desenho dos procedimentos metodológicos 90

3.3.1 A geração dos dados 92

3.4 O universo da pesquisa $\quad 95$

3.4.1 A instituição escolar 95

3.4.2 O ensino de inglês na instituição 96 
3.4.3 Avaliação e engajamento discursivo 99

$\begin{array}{ll}3.5 O \text { perfil dos participantes } & 100\end{array}$

3.5.1 Perfil da professora-pesquisadora 100

$\begin{array}{ll}\text { 3.5.2 Perfil das professoras da equipe do ITB } & 104\end{array}$

3.5.3 Perfil dos alunos da turma ITB $02 \quad 109$

$\begin{array}{ll}\text { 3.6 Desenho do programa de ações pedagógico-discursivas } & 115\end{array}$

4. Sala de aula de ILE em cena: caminhos para sua ressemantização 126

4.1 Movimento 1: Interação mais convencional em operação 128

4.1.1 Design das atividades, textos trabalhados e arranjo espacial da microcena 1

4.1.2 Jogo interacional da sala de aula na microcena 1: Iniciando conversas sobre hábitos alimentares

4.2 Movimento 2: ressemantização preparatória

4.2.1 Design das atividades, textos trabalhados e arranjo espacial da microcena 2

4.2.2 Jogo interacional da sala de aula na microcena 2: opinando sobre imagem corporal na adolescência

4.3 Movimento 3: Ressignificação mais expandida em operação

4.3.1 Design das atividades, textos trabalhados e arranjo espacial da microcena 3

4.3.2 Jogo interacional da sala de aula na microcena 3: Pensando a ordem disciplinar e estereótipos de alunos-professor

4.3.3 Design das atividades, textos trabalhados e arranjo espacial da microcena 4

4.3.4 Jogo interacional da sala de aula na microcena 4:

Estranhamentos e intolerância

4.4 Movimento 4: Interação ressignificada

4.4.1 Design das atividades, textos trabalhados e arranjo espacial da microcena 5

4.4.2 Jogo interacional microcena 5: Refletindo sobre ética e valores

5. Movimentos em diálogo 
8. Anexos

Anexo 1 Atividades da unidade 6 do livro didático 253

Anexo 2 Slides trabalhados na unidade $6 \quad 255$

Anexo 3 Atividades do vídeo Teens' body image 256

Anexo 4 Atividades do filme Dead Poets Society 259

Anexo 5 Atividade de discussão: Estereótipos 262

Anexo 6 Atividades vídeo Strangers 264

Anexo 7 Atividade lúdica - The Emperor's club 267

Anexo 8 Debate sobre o filme The Emperor's club 268

Anexo 9 Slides do debate $\quad 270$

Anexo 10 Questionário 1: Dados Pessoais/Perfil dos Aprendizes 271

Anexo 11 Questionário 2: Feedback dos Aprendizes sobre as atividades desenvolvidas no ano letivo de $2010 \quad 273$

Anexo 12 Questionário 3: Feedback dos professores sobre as atividades desenvolvidas no ano letivo de $2010 \quad 274$ Anexo 13 Extrato 6: Aula de 20/06/10 (Parte 2 do debate) 276 


\section{Lista de quadros}

Quadro 1 - Esquema aula convencional $\quad 50$

Quadro 2 - Princípios constitutivos da PA $\quad 87$

$\begin{array}{ll}\text { Quadro } 3 \text { - Caráter reflexivo da PA } & 88\end{array}$

$\begin{array}{ll}\text { Quadro } 4 \text { - Sequência de uma PA } & 90\end{array}$

Quadro 5 - Fases do ciclo da PA 91

$\begin{array}{ll}\text { Quadro 6 - Perfil dos alunos } & 115\end{array}$

$\begin{array}{ll}\text { Quadro } 7 \text { - Principais pontos da proposta } & 117\end{array}$

Quadro 8 - Textos trabalhados no ano letivo de $2010 \quad 121$

$\begin{array}{ll}\text { Quadro } 9 \text { - Objetivos gerais e específicos das aulas } & 124\end{array}$

Quadro 10 - Movimentos do jogo interacional 126

Quadro 11 - Aula Convencional em operação (Movimento 1) 145

Quadro 12 - Taxonomia Aula Convencional X Aula mais Participativa 160

Quadro 13 - Ações dos debatedores 213

Quadro 14 - Novo papel do aluno 226

Quadro 15 - Mudanças no papel do professor 229 


\section{Lista de figuras}

Figura 1 - Mosaico de imagens midiáticas 33

Figura 2 - Arranjo espacial tradicional 119

Figura 3 - Reorganização do arranjo espacial tradicional 119

Figura 4 - Blog das turmas do nível ITB 120

Figura 5 - Mapa conceitual da análise dos dados 127

Figura 6 - Slide unidade $6 \quad 129$

Figura 7 - Arranjo espacial da aula do Movimento $1 \quad 130$

Figura 8 - Arranjo espacial da microcena $2 \quad 148$

Figura 9 - Arranjo espacial da microcena 3

Figura 10 - Arranjo espacial da microcena 4 (narração do filme) 184

Figura 11 - Arranjo espacial do debate (Emperor's club) 206

$\begin{array}{ll}\text { Figura } 12 \text { - Sala de aula ressignificada } & 231\end{array}$ 


\section{Lista de convenções}

As convenções utilizadas nas transcrições dos dados deste trabalho foram adaptadas do modelo proposto por Tannen; Wallat (2002) e Marcuschi (1998). Os seguintes símbolos foram utilizados:

[ ] falas sobrepostas, ou seja, duas vozes ouvidas ao mesmo tempo;

\section{[ $]$}

= Sinal de igual indica fala encadeada, ou seja, ausência de pausa entre as linhas encadeadas;

((comentários do analista sobre aspectos não linguísticos, sentimentos, gestual));

/palavras/ entre barras refletem transcrições incertas;

/?/ indica palavras inaudíveis ou transcrição impossível;

? indica entonação crescente ou pergunta;

. indica entonação decrescente (e não ponto final sintático);

: seguindo vogais indicam alongamento de som;

/ uma barra indica pausa breve, menos de meio segundo;

// duas barras indicam pausa de no mínimo meio segundo;

[ 1 ] números entre colchetes indicam pausas mais longas de um ou dois segundos ou mais;

$\Rightarrow$ Seta à esquerda indica que a fala do falante continua sem interrupção na sua próxima linha de fala;

Palavra Sublinhada indica ênfase no volume ou na altura;

LETRA maiúscula em negrito indica muita ênfase;

/.../ omissão de trecho não relevante. 
Ensinar não é transferir conhecimento, mas criar as possibilidades para a sua produção ou a sua construção. Ensinar exige reflexão crítica sobre a prática. Ensinar exige compreender que a educação é uma forma de intervenção no mundo.

\section{Paulo Freire}

